DOCTRINA

\title{
Hacia una excepción abierta a los derechos de autor en Chile: Una propuesta normativa a la luz de los usos justos
}

\author{
Towards an open exception to copyright in Chile: \\ A normative proposal in the light of fair uses
}

Carlos Araya Paz

Universidad Adolfo Ibáñez, Chile

\begin{abstract}
RESUMEN El presente artículo propone una normativa de lege ferenda a través de la introducción de una excepción abierta al derecho de autor que, bajo ciertos supuestos, permita el uso de obras protegidas por el derecho de autor por parte de la sociedad en su conjunto, favoreciendo así el tránsito de las ideas y consolidando valores como la libertad de expresión.
\end{abstract}

PALABRAS CLAVE Fair use, derecho de autor, excepciones, propuesta normativa, Chile.

ABSTRACT This article proposes a normative de lege ferenda through the introduction of an open exception to the copyright that, under certain cases, allows the use of copyrighted works by the society as a whole, thus favoring the transit of ideas and consolidating values such as freedom of expression.

KEYWORDS Fair use, copyright, exceptions, normative proposal, Chile.

\section{Introducción}

En 1909, E.M. Forster escribió The Machina stops, un cuento de ciencia ficción situado en un futuro distópico en que las personas viven encerradas en cápsulas subterráneas, donde la comunicación entre ellas se da a través de una red llamada «La Máquina», que además proporciona a las personas de todas las necesidades existentes. La Máquina en un momento colapsa, y el héroe de la historia denuncia esta locura señalando que la Máquina funciona, pero no para los propósitos de los seres humanos. 
La ciencia ficción de 1909 es la realidad de hoy. La Máquina se llama internet, y no sólo ha transformado la forma en que los seres humanos nos comunicamos, sino también la forma en que consumimos distintas clases de bienes, desde bienes materiales como una prenda de vestir, hasta bienes inmateriales como una canción o un poema. Es precisamente en el ámbito de los bienes inmateriales donde internet ha ejercido un impacto sustantivo en la sociedad. Dentro de internet es posible encontrar un acervo no menor de material intelectual propietario, es decir, obras creativas que pertenecen a alguien, tales como canciones, películas, fotografías, etcétera.

En ese contexto, resulta relevante examinar la forma en que las personas interactúan con dichas obras creativas propietarias en la actualidad.

A diferencia de la Máquina de Forster, en la que los habitantes eran pasivos consumidores de contenidos creativos, internet ha sido una herramienta que ha permitido a las personas no solamente consumir contenido creativo, sino crear y divulgar dichos contenidos, tomando un rol activo en la configuración de la realidad cultural de una sociedad.

Sin perjuicio de lo anterior, no toda irrupción tecnológica que transforma a una sociedad conlleva un cambio en las normas legales que regulan a esa sociedad transformada. La ley, generalmente, regula lo ya existente y muy escasamente se anticipa a cambios tecnológicos. ${ }^{1}$ Bajo esa extemporaneidad con que opera la ley, es posible que conductas inexistentes en el pasado hoy sean del todo cotidianas y, sin embargo, sean legalmente reprochables.

Refrenda lo anterior, la ilicitud de las siguientes conductas que vulnerarían el derecho de autor en Chile: i) una madre, con su teléfono móvil, graba a su hija bailando una canción del grupo musical Queen y después sube dicho video a Youtube, sin mediar autorización ni pago de derechos al titular de la canción de Queen; ii) los miembros de una junta de vecinos que organizan una kermés con el fin de recolectar fondos y reproducen dibujos de Disney para la entretención de los menores, sin mediar autorización ni pago de derechos a los titulares de Disney; iii) un joven traduce una canción de su grupo favorito y sube el video a Youtube, sin mediar autorización ni pago del titular de la canción, y iv) un alumno toma apuntes de clases y desea compartirlos con sus compañeros de curso subiendo dicho material a un servicio de nube en la red, sin la autorización del profesor.

¿Es socialmente deseable una ley que sancione conductas como las descritas anteriormente? ¿Todo uso no autorizado de una obra protegida por el derecho de autor causa un perjuicio a su titular? ¿Es posible articular una propuesta normativa de lege ferenda que permita a la ley adaptarse a la tecnología venidera?

1. Prueba de ello es la irrupción de plataformas de tecnológicas de transporte como Uber o Cabify, que motivó, por parte del Ejecutivo, el envío de un proyecto de ley al Congreso que busca regularlas (Boletín 10.937-15, que moderniza la legislación sobre transporte público remunerado). 
Estas son algunas preguntas que este artículo busca responder. Para dichos fines, se estructura en cuatro partes. La primera parte pretende sentar nociones sobre el derecho de autor y su naturaleza jurídica, enfatizando el rol de las excepciones en sede autoral y cuáles son dichas excepciones. En la segunda parte, analizaremos la excepción abierta del fair use en el contexto norteamericano. En la tercera parte, examinaremos en detalle la actual excepción de usos incidentales en Chile, junto con definir las directrices para la elaboración de una propuesta normativa de lege ferenda que viene a cerrar la tercera parte. Finalmente, en la cuarta parte, desarrollaremos las principales conclusiones del presente trabajo.

\section{Naturaleza jurídica del derecho de autor. Excepciones al derecho de autor}

Para elaborar una propuesta normativa, resulta imprescindible determinar con claridad los fundamentos y el objeto de dicha propuesta. En este caso, la propuesta normativa busca establecer una excepción abierta o genérica al régimen autoral vigente en Chile. Para la consecución de dicho fin, es necesario comprender primeramente qué es el derecho de autor y por qué una excepción abierta es una herramienta necesaria - e incluso deseable - para nuestra sociedad.

El derecho de autor es un derecho de propiedad que tienen los autores sobre sus obras de inteligencia en los campos literarios, artísticos y científicos. Dicho derecho de propiedad se encuentra consagrado constitucionalmente en el artículo 19 número 25 de la Constitución Política de la República, reconocido en el artículo 584 del Código Civil y regulado en detalle en la Ley 17.336 sobre Propiedad Intelectual.

La construcción de una normativa en esta materia debe necesariamente ponderar los distintos intereses que convergen en materia autoral. Por un lado, hay un interés particular del titular de la propiedad intelectual (en recompensar la actividad creativa y la innovación; en recompensar el esfuerzo material, moral, dedicación y tiempo invertido en la creación; en reconocer los derechos individuales de creadores, inventores y autores en relación a una explotación pacífica y efectiva del resultado creativo o inventivo; en el acceso a conocimientos y al estado de las ciencias y tecnologías para generar nuevas creaciones e innovaciones productivas); por otro, hay un interés general de la sociedad (en fomentar la actividad creativa y la innovación; en asegurar la libertad de expresión, la conservación de las obras culturales y el acceso a las mismas; en velar por la circulación de la información y el acceso a la tecnología, así como por la divulgación pública del estado de las ciencias y tecnologías; en aumentar el tráfico comercial y cultural con otras naciones; en atraer la inversión y la tecnología extranjeras; en cumplir las normas y estándares internacionales y solucionar las controversias; en definitiva, en contribuir al desarrollo económico, cultural, científico y social del país). La legislación autoral debe propender hacia un equilibrio entre ambos intereses (Schmitz, 2009). 
La consecución de dicho equilibrio no es una labor fácil, dado el carácter generalmente antagónico que existe entre los intereses particulares e individuales, y por la intervención de intermediarios - muchas veces necesarios- entre los creadores/ inventores y la sociedad (Schmitz, 2009). El problema yace en que la influencia de estos intermediarios, junto con una tradición autoral continental, ha inclinado la balanza hacia el lado de los titulares, en desmedro de la sociedad como parte integrante del binomio autoral.

Sin perjuicio de lo anterior, la ley establece ciertos mecanismos que sirven de contrapeso a la visión unilateral de la propiedad intelectual. Dentro de dichos mecanismos encontramos: un plazo prudente para la protección de obras (esto es, fortalecimiento del dominio público); el principio de agotamiento de los derechos de propiedad intelectual, y las limitaciones y excepciones a los derechos de autor.

El presente artículo está estructurado en base a uno de estos mecanismos de contrapeso autoral: las limitaciones y excepciones a los derechos de propiedad intelectual.

\section{Excepciones y limitaciones al derecho de autor}

Cuando en derecho hablamos de excepciones, la primera asociación que es posible formular nos conduce a las excepciones como medios de defensa en materia procesal, las que pueden ser definidas como una defensa del demandado en un eventual litigio, basada en elementos de hecho y de derecho que tienen por objeto corregir vicios del procedimiento o provocar una eficacia extintiva, impeditiva o invalidativa de lo afirmado como fundamento de la pretensión.

En material autoral, las excepciones y limitaciones a los derechos de propiedad intelectual comparten esa misma noción: un medio de defensa que tiene el demandado frente a una eventual infracción de los derechos de autor, que corresponde a hipótesis en las que puede hacerse uso de obras protegidas por el derecho de autor — es decir, las que aún no se integran al dominio público- sin obtener licencias o autorizaciones por parte de sus autores o titulares de derechos de autor (Álvarez Valenzuela y Correa Pérez, 2017).

En ese sentido, es preciso entender a las excepciones y limitaciones a los derechos de propiedad intelectual como el correlato directo de los derechos que se le confieren al creador. Como dos caras de la misma moneda. Lo anterior se ve refrendado al analizar lo prescrito tanto en la Declaración Universal de Derechos Humanos (artículo 27), como en el Pacto Internacional de Derechos Económicos, Sociales y Culturales (artículo 15), que incluyen en un mismo artículo, mediante dos párrafos, el derecho de toda persona a la protección de los intereses morales y materiales que le corresponden por razón de las producciones científicas, literarias o artísticas de que sea autora, y el derecho de toda persona a tomar parte libremente en la vida cultural de 
la comunidad, a gozar de las artes y a participar en el progreso científico y en los beneficios que de él resulten.

Lo anterior refleja claramente la necesidad de buscar un adecuado equilibrio en la construcción de una normativa autoral que permita, por una parte, estimular la creatividad de los autores y asegurarles que siguen la suerte económica de su creación; y, por la otra, facilitar al colectivo social el acceso a los bienes culturales, sin desmedro de aquella protección.

De allí que todas las legislaciones del mundo, al tiempo que le reconocen al creador el derecho exclusivo de explotar su obra, dejan a salvo un conjunto de excepciones, conocidas como limitaciones al derecho patrimonial exclusivo.

La importancia de las excepciones en el progreso cultural es crucial. Si fuese necesario pedir autorización al titular cada vez que un documento es reproducido para uso educacional, cada vez que citamos o cada vez que una imagen es incorporada en un trabajo, los costos y las dificultades para encontrar a los titulares, negociar las licencias y pagar por ellas obstaculizaría gravemente nuestra habilidad para compartir las ideas y acceder a la información (Heins y Beckles, 2005).

La naturaleza de las excepciones y limitaciones al derecho de autor presenta variaciones dependiendo del sistema autoral que estudiemos. Así, el sistema continental del derecho de autor se caracteriza por contener una lista taxativa de aquellas actividades que limitan al derecho de autor (Walker, 2014: 27). Generalmente se repiten ciertas hipótesis de limitación al derecho de autor entre los países de la tradición continental, relacionadas con aspectos tales como reproducciones provisionales, copia privada, discapacidades, cita e ilustración de la enseñanza, informaciones de actualidad, bibliotecas y archivos, y parodia (Walker, 2014: 27). Esta clase de excepciones se denominan «cerradas o circunscritas» a determinados usos, porque autorizan ciertos usos específicos de una obra protegida, bajo ciertas circunstancias previamente definidas de forma clara en la norma autoral. La razón que subyace a la existencia de este tipo de excepciones en el sistema continental, a nuestro juicio, reside en la necesidad de una certeza jurídica para las personas que consumen bienes intelectuales, de forma tal que, con la mera lectura de la norma jurídica, puedan deducir con claridad si una determinada conducta se encuentra o no amparada por la excepción.

El sistema anglosajón del derecho de autor, por su parte, contiene dos clases de excepciones: por un lado, consagra excepciones cerradas como las mencionadas anteriormente; por otro lado, consagra una excepción abierta o general, diseñada para otorgar una mayor flexibilidad a la normativa autoral, no ceñida a usos determinados, sino a una generalidad de usos, toda vez que concurran los requisitos que la misma ley establece. La regulación norteamericana consagra, así, la denominada excepción de uso justo (fair use), la regulación inglesa consagra la excepción de trato justo (fair dealing) y, por último, el derecho internacional consagra el criterio normativo de la «regla de los tres pasos». 


\section{Sistemas de excepciones abiertas: la regla de los tres pasos y el fair use}

\section{Regla de los tres pasos}

La regla de los tres pasos se originó en 1967, durante la Conferencia de Estocolmo, en la cual se revisó el Convenio de Berna para la Protección de las Obras Literarias y Artísticas de 1886. La norma, contenida en el artículo 9 numeral 2, dispone de tres «pasos» copulativos que se deben seguir para determinar si el uso que se realiza de una obra protegida por el derecho de autor, sin autorización del titular de la misma, es o no legítimo. Estos tres pasos son:

1) debe tratarse de un uso circunscrito a ciertos casos especiales, 2) debe ser un uso que no atente contra la explotación normal de la obra, y 3) debe ser un uso que no cause un perjuicio injustificado a los intereses legítimos del autor.

Hacemos presente que el precepto ha sido reproducido en una serie de instrumentos internacionales, entre los que destacan: el artículo 9 numeral 2 del Convenio de Berna; el artículo 13 del Convenio sobre los Aspectos de los Derechos de Propiedad Intelectual relacionados con el Comercio (ADPIC); ${ }^{2}$ el artículo 10 del Tratado de la Organización Mundial de la Propiedad Intelectual (OMPI) sobre Derecho de Autor; el artículo 16 del Tratado de la OMPI sobre Interpretación o Ejecución y Fonogramas; y el artículo 5 numeral 5 de la Directiva 2001/29/CE del Parlamento Europeo y del Consejo del 22 de mayo de 2001 relativa a la armonización de determinados aspectos de los derechos de autor y derechos afines a los derechos de autor en la sociedad de la información, entre otros.

La regla de los tres pasos, como criterio normativo, ha resultado deficiente por una serie de factores que sintetizaremos en tres puntos (Senftleben, 2010).

- Al ser un estándar normativo internacional, no existe una interpretación uniforme de la norma, quedando ésta entregada al criterio interno de los países que adoptan la regla de los tres pasos. Lo anterior incide en que, frente a un mismo caso, la aplicación de la regla puede variar de país en país. Ello, naturalmente, genera una incerteza jurídica no deseada como técnica normativa.

- La regla de los tres pasos se ha incorporado, en los países europeos, como un requisito adicional que deben cumplir las excepciones cerradas o circunscri-

2. La gran diferencia con el artículo 13 del ADPIC es la introducción de un lenguaje distinto, que genera distintos efectos. Pues mientras el Convenio de Berna requiere que la excepción «no cause un perjuicio injustificado a los intereses legítimos del autor», la regla establecida en el ADPIC requiere que la excepción «no cause un perjuicio injustificado a los intereses legítimos del titular del derecho». Esta sutil modificación desvía la atención desde los creadores hacia los intermediarios, que muchas veces detentan el rol de titulares de derechos de autor (generalmente vía contractual). 
tas. Es decir, por ejemplo, la excepción de comunicación al público de obras en beneficio de personas minusválidas, que guarde relación directa con la minusvalía y no tenga carácter comercial, debe además no entrar en conflicto con la explotación normal de la obra o prestación y no perjudicar injustificadamente los intereses legítimos del titular de los derechos. ${ }^{3}$ Lo anterior, naturalmente, hace que en la práctica resulten inaplicables las excepciones al derecho de autor. Si las excepciones circunscritas buscan dar certeza jurídica tanto a los usuarios de obras como a sus titulares, la incorporación de la regla como un requisito adicional que deben cumplir las excepciones cerradas no solo genera incerteza jurídica respecto de las excepciones cerradas, sino que además da lugar a una falta de flexibilidad que precisamente las excepciones abiertas buscan otorgar para adaptarse a los sucesivos cambios tecnológicos.

- Relacionado con el punto anterior, la aplicación práctica en los tribunales en que se ha invocado como medio de defensa ha sido sumamente restringida y fallando contra el que invoca la excepción. Dicho enfoque se podría explicar por dos elementos: de acuerdo a lo mencionado, la regla se ha incorporado como un requisito adicional a satisfacer por las excepciones circunscritas que contiene cada legislación; y porque la tradición histórica a la que pertenece la regla es la tradición continental de derecho de autor, en la que el juez debe ceñirse estrictamente a lo dispositivo de la norma, sin poder apartarse de su tenor para crear nuevas excepciones conforme lo exija el caso sub lite, lo que ha derivado en la incapacidad de la norma para adaptarse a los sucesivos cambios tecnológicos (Senftleben, 2010).

\section{Fair use}

El fair use, por su parte, es el correlato norteamericano de la regla de los tres pasos, con una salvedad digna de mencionar: es una creación jurisprudencial que data de 1740, cuyas bases se delinean en 1841 con el caso Folsom con Marsh y adquiere asidero normativo en 1976, es decir, estamos frente a una norma que se ha ido desarrollando y aplicando sistemáticamente por los tribunales de justicia norteamericanos, 220 años antes que la misma regla de los tres pasos.

El fair use fue plasmado normativamente en la Sección 107 del Copyright Act de $1976,{ }^{4}$ el cual podemos desglosar en tres componentes:

3. Directiva 2001/29/CE del Parlamento Europeo.

4. «Sin perjuicio de lo dispuesto en las secciones 106 y 106A, el uso justo de una obra protegida por el derecho de autor, incluido su uso mediante reproducción en copias o fonogramas o por cualquier otro medio especificado por dicha sección, con fines tales como críticas, comentarios, (incluidas copias múltiples para uso en el aula), becas o investigaciones, no constituye una infracción del derecho de autor. 
- Una declaración de que el fair use (uso justo) de una obra protegida por el derecho de autor no es una infracción a la normativa autoral.

- Una lista ilustrativa - y no exhaustiva- de seis usos de obras que podrían ser calificados de fair use (crítica, comentario, periodístico, enseñanza, interés académico e investigación).

- Un catálogo de cuatro factores que los tribunales deben tener en cuenta para considerar si el uso de una obra protegida por el derecho de autor es subsumible o no, en la esfera del fair use: a) el propósito y carácter de la utilización, incluyendo la determinación de si dicha utilización es de una naturaleza comercial, educacional o sin fines de lucro; b) la naturaleza de la obra; c) la cantidad e importancia de la porción utilizada de la obra original protegida; c) el efecto de dicho uso en el mercado actual y potencial de la obra protegida o en su valor.

\section{Regla de los tres pasos y su interacción con el fair use}

Como es posible advertir, en su origen, ambas excepciones difieren. Mientras la regla de los tres pasos fue concebida como una excepción normativa de carácter abierto para ser aplicada en distintos países, el fair use fue concebido en un país para ser aplicado en el mismo, de acuerdo a su realidad.

Estados Unidos se adhirió al Convenio de Berna el 16 de noviembre de 1988. Surge naturalmente la interrogante respecto de cómo interactúa la excepción abierta local del fair use con la excepción abierta internacional de la regla de los tres pasos.

Sobre el particular, hacemos presente que la regla contenida en el Convenio de Berna opera como un estándar normativo que busca asegurar ciertos límites en la creación de excepciones. Por lo mismo, este criterio no se opone al fair use, sino que sirve de base para que los países adherentes al Convenio formulen sus excepciones al derecho de autor.

En tal sentido, el fair use norteamericano cumple con el estándar normativo contenido en el Convenio de Berna, en la siguiente forma: i) con el primer paso del

Para determinar si el uso que se hace de una obra en un caso particular es un uso justo, los factores a considerar incluirán:

1) el propósito y carácter de la utilización, incluyendo la determinación de si dicha utilización es de una naturaleza comercial, educacional o sin fines de lucro;

2) la naturaleza de la obra protegida por el derecho de autor;

3) la cantidad e importancia de la porción utilizada de la obra protegida; y

4) el efecto de dicho uso en el mercado actual y potencial de la obra protegida o en su valor.

El hecho de que una obra no sea publicada no impedirá por sí mismo una constatación de uso justo si tal constatación se efectúa teniendo en cuenta todos los factores antes mencionados". (La traducción es nuestra.) 
Convenio (que el uso de la obra protegida de circunscriba a ciertos casos especiales) cumple a través de los usos que son susceptibles de ser considerados justos (crítica, comentario, periodístico, enseñanza, interés académico e investigación); ii) con el segundo paso del Convenio (que el uso de la obra protegida no atente contra la explotación normal de ella) cumple en la forma en que se aplica el fair use, no siendo éste aplicable cuando atenta contra la explotación normal de la obra; y, finalmente, iii) el fair use no causa un perjuicio injustificado a los intereses legítimos del autor (Samuelson, 2015: 26).

\section{Elección del fair use como base para una propuesta normativa}

En virtud de lo anteriormente expuesto, la elección del fair use como base para la elaboración de una propuesta de lege ferenda descansa en los siguientes argumentos:

- La principal ventaja del fair use sobre la regla de los tres pasos descansa en el fuerte desarrollo jurisprudencial de la excepción norteamericana. En efecto, la jurisprudencia norteamericana le ha dado forma a la excepción del fair use desde 1841, es decir, cuarenta y cinco años antes del primer texto del Convenio de Berna. En consecuencia, es dable señalar que el fair use cuenta con una tradición jurídica mucho más robusta y desarrollada con la cual dialogar al momento de crear una excepción abierta.

- La forma en que se ha construido el fair use y la jurisprudencia que ha delimitado su alcance han permitido que la excepción norteamericana logre adaptarse, con cierta facilidad, a las irrupciones tecnológicas que han influido en la configuración del derecho de autor. ${ }^{5}$

- Atendida su tradición histórica y el consecuente desarrollo jurisprudencial, el fair use se ha convertido en una verdadera normativa de exportación para la elaboración de excepciones similares en otras legislaciones. Ejemplos de ello son el caso de Israel y, en cierta forma, el de Brasil.

- El fair use ha contribuido poderosamente al desarrollo económico de Estados Unidos. Circunstancia del todo relevante, pues el desarrollo económico

5. La flexibilidad del fair use se aprecia en la historia de la Copyright Act de 1976 de Estados Unidos, en que el Congreso optó por una formulación flexible que se adapte al dinamismo de la tecnología: «The bill endorses the purpose and general scope of the judicial doctrine of fair use, but there is no disposition to freeze the doctrine in the statute, especially during a period of rapid technological change. Beyond a very broad statutory explanation of what fair use is and some of the criteria applicable to it, the courts must be free to adapt the doctrine to particular situations on a case-by-case basis». Copyright Law Revision (House Report 94-1.476) (Representatives s.f.). 
no sólo se ha traducido en un beneficio económico para el creador, sino que ha irradiado a la sociedad en su integridad. ${ }^{6}$

- Nuestra legislación autoral -que data de 1970- no contemplaba ninguna norma de excepción abierta, por el contrario, contaba con un catálogo muy reducido de excepciones circunscritas a ciertos derechos de autor. Su omisión se trató de subsanar mediante la reforma legal que se llevó a cabo durante el año 2010, mediante la cual se buscaba incorporar un set más amplio y robusto de excepciones a los derechos de propiedad intelectual. En plena discusión de dicha reforma legal, se vislumbró seriamente el adoptar un modelo de excepción abierta de fair use. La posibilidad real de contar por primera vez con una excepción abierta — concebida a imagen y semejanza del fair use- dentro de nuestra legislación, y que viniera a suplir un vacío legal, es un indicador de la importancia que han adquirido los usos justos, ya en un contexto global.

No obstante lo anterior, a nuestro juicio, la excepción abierta que se trató de articular en Chile - fruto de la reforma legal previamente aludida - si bien constituyó un notable avance, dista de ser realmente una excepción abierta, motivo por el cual en este trabajo se busca elaborar una nueva proposición normativa de excepción abierta que supere los defectos observados en la norma que actualmente nos gobierna.

\section{Fair use: análisis de los cuatro factores}

Los cuatro factores contemplados en la Sección 107 del Copyright Act norteamericano que deben ser ponderados por el juez al momento de determinar si un uso es o no justo, son:

- el propósito y carácter de la utilización, incluyendo la determinación de si dicha utilización es de una naturaleza comercial, educacional o sin fines de lucro;

- la naturaleza de la obra protegida;

- la cantidad e importancia de la porción utilizada de la obra protegida; y

- el efecto de dicho uso en el mercado actual y potencial de la obra protegida o en su valor.

6. En tal sentido, cabe destacar el informe elaborado por la Computer \& Comunication Industry Association (CCIA) en el 2010 sobre la importancia del fair use en el desarrollo de la industria tecnológica en Estados Unidos. Las empresas asociadas al fair use aportan el equivalente al 16,2\% del total del PIB del país, sólo en el año 2007. Del mismo modo, en materia de empleo, las industrias relacionadas con el fair use incrementaron el número de empleos desde 16,9 millones en el 2002 a 17,5 millones en 2007. Así, aproximadamente uno de cada ocho trabajadores en los Estados Unidos es empleado en alguna industria que se beneficia de la protección conferida por el fair use (Rogers y Szamosszegi, 2007). 
Cabe hacer presente que el juez tiene un amplio rango de discreción a la hora de ponderar los factores antes mencionados, pudiendo - en ciertas ocasiones- no mesurar igualmente los cuatro elementos o, incluso, incorporar distintas consideraciones no recogidas en el texto legal. Del mismo modo, para que se logre demostrar la existencia del fair use no es necesario que el demandado tenga que probar la concurrencia de cada uno de los cuatro factores: la determinación del fair use puede descansar sólo en un factor, si éste logra generar la suficiente persuasión en el sentenciador. Sin ir más lejos, pese a lo que prescribe el tercer factor (la cantidad e importancia de la porción utilizada en relación con la obra original protegida como un todo), la copia íntegra de una obra puede, en algunos casos, constituir fair use. ${ }^{7}$

\section{Primer factor: propósito y carácter de la utilización}

\section{Uso transformador}

Un uso es transformador cuando modifica, altera o transforma la obra protegida por el derecho de autor en una obra nueva, o le añade una nueva utilidad a la obra original (Crews, 2017). Así, por ejemplo, si alguien toma fragmentos de discursos dados por el presidente de Estados Unidos y el presidente de Rusia y los mezcla generando una canción romántica, es probable que esa transformación que se hace le brinde una nueva perspectiva a la obra original (comentario) y, en consecuencia, sea más susceptible de ser considerada como un uso justo.

\section{Usos con propósitos educacionales}

La enseñanza, el interés académico y la investigación forman parte de los usos que la ley menciona como susceptibles de ser considerados como usos justos. Los usos con propósitos educacionales en materia de fair use han enfrentado dos grandes obstáculos: a) la ausencia de una definición normativa de usos educacionales y b) el desarrollo jurisprudencial que han tenido los usos con propósitos educacionales.

En relación con el primer obstáculo previamente referido, la Oficina de Copyright de la Biblioteca del Congreso de Estados Unidos ha elaborado pautas para que los académicos, investigadores y estudiantes sepan con mediana certeza qué usos generan mayor conflicto con la ley autoral, las cuales han sido recopiladas en la denominada Circular 21. ${ }^{8}$

7. La Corte Suprema falló en 1984 que la copia íntegra de un programa de televisión con el fin de poder verlo después en casa constituía fair use. Véase Sony Corp. of America con Universal City Studios Inc., Corte Suprema de los Estados Unidos, 1984. Disponible en http://bit.ly/1Pfg3qu.

8. Las pautas que establece la Circular 21 no son parte del Copyright Act, sino que son pautas reconocidas por los jueces como estándares mínimos para el fair use en materia educacional. Las pautas 
En relación con el segundo obstáculo, las demandas por usos con propósitos educacionales escasamente han logrado tener éxito en juicio. ${ }^{9}$ Uno de los casos más emblemáticos fue Williams \& Wilkins Co. con Estados Unidos. ${ }^{10}$ Lippincott Williams \& Wilkins es una importante editorial de revistas de investigación médica que demandó al Gobierno de Estados Unidos fundando su demanda en que la biblioteca del National Institutes of Health (NIH) y la National Library of Medicine (NLM) estaban sistemáticamente infringiendo su derecho de autor, mediante la fotocopia no autorizada de artículos que figuraban en las publicaciones del demandante. Williams \& Wilkins ganó en primera instancia. Sin embargo, el Gobierno apeló a dicha decisión y, en un dividido fallo de apelación, se resolvió a favor del Gobierno y su defensa del fair use. El voto de mayoría le otorgó un peso considerable a los beneficios al progreso de la ciencia que derivan del programa de fotocopias de la NIH y de la NLM.

\section{Usos con propósitos no comerciales}

La distinción entre usos comerciales y usos no comerciales deriva de la decisión de la Corte Suprema de Estados Unidos en un caso paradigmático en materia de fair use: Sony Corp. of America con Universal City Studios Inc.

En 1970, Sony desarrolló Betamax, una videograbadora que posteriormente daría paso al VHS. El desarrollo de esta nueva tecnología hizo que la industria cinematográfica y del entretenimiento reaccionara ante lo que aparentemente constituía una amenaza contra los contenidos protegidos por el copyright que ellos producían. Fue así como Disney y Universal demandaron a Sony por responsabilidad secundaria ${ }^{11}$

educacionales son similares a un acuerdo adoptado entre los titulares de derecho de autor y los académicos, bajo el cual los titulares permiten los usos establecidos en las pautas. Hacemos presente que dichas directrices no son vinculantes para los jueces, sino que son meras guías ilustrativas (Oficina de Copyright de Estados Unidos, 1983).

9. Las razones descansarían — según Samuelson - en que, en primer lugar, los casos de copias para propósitos de enseñanza son a menudo hechos en privado y con fines no comerciales (ello hace que sea difícil detectar una infracción al copyright). En segundo lugar, los costos de ejecución o tratar de licenciar muchos de esos usos con propósitos educacionales serían demasiado elevados (altos costos de transacción). Por último, mucha de esas copias serían usos razonables y consuetudinarios que deberían ser considerados fair use, y eso es algo que los editores han aceptado (Samuelson, 2009: 39).

10. Williams \& Wilkins Co. con Estados Unidos, Corte Suprema de Estados Unidos, 487 F.2d 1345, 1975.

11. Las teorías de responsabilidad secundaria son aquellas que buscan establecer la responsabilidad de una persona distinta a la que cometió la infracción en forma directa, pero que, por su particular relación con el infractor, es que se considera que dicha persona ha podido evitar la comisión de la infracción. Esta teoría de responsabilidad secundaria puede ser: a) responsabilidad contributiva (es la que existe cuando el demandado tiene conocimiento de la actividad ilícita que está realizando un tercero y el demandado ha contribuido en forma importante a la realización de la misma), y b) responsabilidad vicaria (es la que existe cuando el demandado recibe un beneficio económico de la actividad ilícita cometida por un tercero, y además el demandado tiene el derecho o la capacidad para controlar la actividad del 
derivada del uso ilegal que presuntamente hacían los usuarios de la tecnología Betamax. Los demandantes alegaban que Sony producía un aparato que permitía que los consumidores se dedicaran a la violación del copyright. Ello debido a que el aparato elaborado por Sony tenía un botón de grabación que le permitía al usuario grabar películas y programas protegidos por el derecho de autor. Sony, por tanto, se estaba beneficiando de las supuestas violaciones del copyright de sus clientes.

La Corte de Apelaciones del Noveno Circuito concluyó que Sony era responsable de las violaciones al derecho de autor permitidas por sus máquinas, asumiendo así -erróneamente-la presunción de que todo uso comercial podría ser injusto (Leval, 1997: 1451).

Sin embargo, la Corte Suprema de Estados Unidos revocó esta decisión basado en que la existencia de potenciales usos infractores no constituía una tecnología ilegal per se. La Corte prohibió establecer responsabilidad secundaria cuando la tecnología tenía importantes usos no infractores (substantial noninfringing uses) y añadió que los consumidores tenían derecho - bajo la doctrina del fair use - a efectuar time shifting, esto es, a grabar un programa para verlo en forma privada en un horario distinto.

El fallo de la Corte hizo énfasis en el primer y cuarto factor del fair use, que favorecían a los usuarios de las videograbadoras. En lo que guarda relación con el primer factor, la Corte - al efectuar el análisis - se cuestionó si los televidentes estaban o no haciendo un uso comercial de los programas transmitidos (si fuese un uso comercial sería presumiblemente una infracción al copyright). La Corte concluyó que los televidentes, en este caso, usaban el dispositivo Betamax para time shifting y, por lo mismo, el uso no era comercial. Luego, en el examen del cuarto factor, llegó a la conclusión que el time shifting no implicaba una pérdida de ingresos para los propietarios del copyright, ya que los auspiciadores estarían seguros de que los programas que ellos auspiciaban aún se seguirían viendo y, por consiguiente, el mercado para sus productos no tendría alteraciones significativas.

\section{Segundo factor: la naturaleza de la obra protegida}

Este segundo factor atiende a las características propias de la obra utilizada, es decir, si se trata de una obra de ficción o si se trata de una obra basada en hechos, o si la obra se encuentra publicada o es inédita.

El criterio adoptado por los tribunales respecto de este factor es que, en la medida que una obra contenga una mayor creatividad, mayor será la protección que reciba de la propiedad intelectual. Por lo mismo, el uso no autorizado de un poema o una

infractor, como, por ejemplo, mediante la terminación de un contrato de servicios) (Magliona y Lopez, 2010: 70). 
canción es más susceptible de ser considerado injusto a la luz del fair use. Por el contrario, si se utilizaron datos fácticos o basados en hechos, como ocurre, por ejemplo, en un ensayo científico o en un informe técnico, la posibilidad de estar amparado por la doctrina del fair use es mayor. El argumento que yace tras la distinción entre obras creativas y fácticas es que las últimas requerirían menos imaginación del autor y tendrían mayor valor para las futuras generaciones de autores y estudiosos que necesiten acceso a esas obras (Madison, 2004: 1.559).

Tercer factor: la cantidad e importancia de la porción utilizada de la obra protegida

La cantidad e importancia referida en este tercer factor debe entenderse tanto desde una perspectiva cuantitativa como cualitativa. La determinación cualitativa del extracto de la obra protegida por el derecho de autor se efectúa en atención a lo que la jurisprudencia ha denominado el corazón de la obra (entendido esto como la esencia de la misma). Según Madison, sería el foco de la creatividad expresada en la obra, o la porción de la obra que tenga el mayor valor económico (Madison, 2004: 1.561). Así, por ejemplo, el empleo del riff inicial de Beat it de Michael Jackson o el instante en que el personaje de la saga de La guerra de las galaxias, Darth Vader, revela su paternidad al personaje de Luke Skywalker. La determinación cuantitativa de un uso, por otro lado, debe ser evaluada en relación con la extensión total de la obra original. Del mismo modo, debe ser una cantidad necesaria para servir al objetivo específico que se busca con la utilización de la obra. Sería un uso desproporcionado y mera copia el empleo - por ejemplo— de la totalidad de la novela Rayuela de Cortázar.

\section{Cuarto factor: el efecto de dicho uso en el mercado actual y potencial de la obra protegida o en su valor}

El cuarto factor busca determinar cuál es el efecto en el mercado del uso no autorizado de una obra. Para ello, el sentenciador evalúa si el uso priva al derechohabiente de ingresos o socava un nuevo o potencial mercado del bien intelectual (Stim, 2010). Por consiguiente, no es necesario que el daño sea actual, puede incluso ser un daño a mercados nuevos o potenciales. Ello porque la actividad del infractor podría - eventualmente- haber impedido al demandante el desarrollo legítimo de nuevas fuentes de ingreso.

Ahora bien, la forma en que un uso no autorizado afecta el mercado actual o potencial del derechohabiente se da a través de dos maneras: a) compitiendo con la obra original (competencia que se da respecto de bienes sustitutivos y no respecto de bienes complementarios) y b) evadiendo el pago de los derechos de licencia respectivos.

De acuerdo a lo previamente expuesto, el fair use es una excepción abierta a los 
derechos de autor que se ha consolidado en el tiempo como un sólido estándar normativo de excepción autoral, con un robusto desarrollo jurisprudencial, y cuyo contenido ha sido replicado por distintos países. Ejemplo de lo anterior son los casos de Israel y Brasil, que han elaborado excepciones abiertas a la luz de los usos justos norteamericanos. Cabe, en lo sucesivo, determinar el panorama actual de la propiedad intelectual y de las excepciones al derecho de autor en Chile, para fijar las bases sobre la que se construirá nuestra propuesta normativa de lege ferenda, que cerrará el próximo capítulo.

\section{Construcción de una excepción abierta en Chile}

\section{La propiedad intelectual en Chile: una breve reseña histórica}

La primera ley propiamente tal sobre propiedad intelectual fue la Ley sobre Propiedad Literaria y Artística del año 1834. Luego, sucedieron una serie de reformas legales, que derivaron en la promulgación de la Ley 17.336 sobre Propiedad Intelectual en 1970, integrando así a Chile en el esquema internacional a través de la firma de los tratados de Berna en 1974, de la Convención Universal en 1975 y del Convenio de Roma en 1975.

Desde 1970 hasta el 2010, ha habido una serie de reformas legales. La primera reforma se produce en virtud de la Ley 18.443 de 1985 . El norte de dicha primera reforma consistió en el establecimiento de medidas de protección para los programas computacionales, medidas contra los usos no autorizados y un catálogo de penas frente a las infracciones de la ley autoral. La segunda reforma se produce en 1990 a través de la Ley 18.957, que precisó algunos términos de la ley, modificó otros e incorporó incisos en relación con los programas computacionales. La tercera reforma se da con la Ley 19.166, promulgada el 9 de septiembre de 1992. Dicha modificación legal tuvo dos grandes ejes: alteró severamente el artículo 10 de la Ley 17.336, que se refería al plazo de protección de las obras, y estableció en Chile la gestión colectiva, germen de lo que después sería la Sociedad Chilena del Derecho de Autor (SCD). Con el advenimiento del nuevo mileno, se aproxima también la firma de importantes tratados bilaterales como el firmado con Estados Unidos en el 2003. En virtud de dicho tratado se introducen una serie de modificaciones a la Ley 17.336, plasmadas en la Ley 19.914 de 2003, que extienden el plazo de protección de las obras desde cincuenta a setenta años post mortem.

Como es posible apreciar, desde sus orígenes, la ley autoral en Chile había seguido un camino disímil en cuanto al equilibrio que debiese imperar en materia autoral: se había protegido exclusivamente a los titulares (en desmedro de los demás actores), se habían incrementado las penalidades en caso de infracción y, por último, se habían aumentado sucesivamente los plazos de protección de las obras, pero no se habían 
tratado las excepciones, que constituyen un contrapeso necesario en sede autoral. La búsqueda de este balance dará pie posteriormente a la modificación introducida por la Ley 20.435 del año 2010, que, entre otras cosas, incorporó un robusto set de excepciones circunscritas al derecho de autor, entre ellas, una excepción circunscrita de usos incidentales que buscó ser fair use, pero no pudo y cuyo análisis en detalle se efectuará posteriormente.

Excepciones circunscritas al derecho de autor en chile

Excepciones y limitaciones circunscritas bajo la Ley 17.336

Si bien el presente trabajo se centra en las excepciones abiertas y, más particularmente, en la elaboración de una propuesta de lege ferenda de excepción abierta a la luz de los usos justos, es menester referirse - aunque sea brevemente- a las demás excepciones que contempla nuestra legislación.

Las excepciones establecidas en la Ley 17.336, previa a la modificación de la Ley 20.435, eran las siguientes:

- derecho de cita;

- publicación de conferencias y discursos con fines de información;

- lecciones que se imparten en recintos educacionales;

- utilización de fonogramas o partituras en determinados establecimientos comerciales;

- reproducción de obras arquitectónicas;

- reproducción de obras artísticas expuestas en lugares públicos;

- modificaciones de obras arquitectónicas, y

- copias de programas computacionales.

Excepciones y limitaciones circunscritas bajo la modificación introducida por la Ley 20.435

Las excepciones y limitaciones circunscritas introducidas por la Ley 20.435 son las siguientes:

- Derecho de cita.

- Reproducción, distribución o adaptación en beneficio de personas con discapacidad visual, auditiva, o de otra clase.

- Reproducción efectuada por bibliotecas de obras no disponibles en el mercado. 
- Reproducción de fragmentos de obras por bibliotecas para uso personal del usuario.

- Reproducción electrónica dentro de bibliotecas y archivos.

- Cita de obras de carácter plástico, fotográfico o figurativo en el marco de la educación formal.

- Reproducción provisional (de carácter transitorio o accesorio) dentro de un proceso tecnológico dirigido a la transmisión u otro uso lícito, sin significación económica independiente.

- Reproducción y comunicación pública para actuaciones judiciales, legislativas y administrativas.

- Las lecciones dictadas en instituciones de educación superior, colegios y escuelas pueden ser anotadas o recogidas en cualquier forma, pero no pueden ser publicadas sin consentimiento del autor.

- Reproducción de obras de arquitectura por medio de la fotografía, el cine, la televisión y cualquier otro procedimiento análogo.

- Reproducción de monumentos, estatuas y, en general, las obras artísticas que adornan permanentemente plazas, avenidas y lugares públicos, mediante la fotografía, el dibujo o cualquier otro procedimiento.

- En las obras de arquitectura, el autor no podrá impedir la introducción de modificaciones que el propietario decida, pero podrá oponerse a la mención de su nombre como autor del proyecto.

- Traducción de obras originalmente escritas en idioma extranjero por bibliotecas y archivos que no tengan fines lucrativos.

- Programas de computación: a) la adaptación o copia efectuada por su tenedor, siempre que sea esencial para su uso, archivo o respaldo; b) la adaptación para efectuar ingeniería inversa sobre una copia obtenida legalmente de un programa computacional; c) las actividades sobre una copia con el propósito de probar, investigar o corregir su funcionamiento o seguridad, del mismo u otros programas, de la red o del computador. La información sólo podrá ser utilizada para los fines antedichos.

- Traducción de obras en idioma extranjero para uso personal.

- Parodia o sátira, siempre que se diferencie de la obra original.

- Comunicación al público en beneficio de personas con discapacidad visual, auditiva o de otra clase. 
- Demostraciones en establecimientos comerciales en que se expongan y vendan instrumentos musicales, aparatos de radio o televisión o cualquier equipo que permitan la emisión de sonidos o imágenes, inclusive computadores o programas computacionales, con el exclusivo objeto de efectuar demostraciones.

- Comunicación o ejecución pública sin fines lucrativos dentro del núcleo familiar, de establecimientos educacionales, de beneficencia y otros.

- Obras de arquitectura: la publicación de las correspondientes fotografías en diarios, revistas, libros y textos destinados a la educación.

Como es posible apreciar, el catálogo de excepciones autorales circunscritas introducidas en virtud de la Ley 20.435 fortalece el set existente previamente. Lo anterior propende al equilibrio, señalado al principio de este trabajo, entre un adecuado nivel de protección de los derechos de los titulares sin afectar la libertad y los derechos de los usuarios y consumidores (Álvarez Valenzuela, 2011). Cabe, en lo sucesivo, analizar pormenorizadamente la excepción abierta introducida en virtud de la Ley 20.435.

\section{La «excepción abierta» del artículo 71 letra q) bajo la Ley 20.435: ¿Usos justos?}

La «excepción abierta o flexible» incorporada en el artículo 71 letra q) de la Ley 17.336, está expresada en los siguientes términos:

Es lícito el uso incidental y excepcional de una obra protegida con el propósito de crítica, comentario, caricatura, enseñanza, interés académico o de investigación, siempre que dicha utilización no constituya una explotación encubierta de la obra protegida. La excepción establecida en este artículo no es aplicable a obras audiovisuales de carácter documental. ${ }^{12}$

Es posible apreciar que no estamos frente a una excepción abierta o genérica propiamente tal, sino ante una excepción circunscrita de usos incidentales que replica ciertos elementos del fair use. La norma, por lo demás, adolece de una serie de imprecisiones en la técnica legislativa utilizada, que analizaremos a continuación.

12. Cabe hacer presente que el proyecto originalmente no había contemplado el artículo 71 letra q) en los términos que hemos mencionado, sino que recogía una norma similar en el artículo 71 letra r), que básicamente reproducía lo prescrito por la regla de los tres pasos del Convenio de Berna. En tal sentido, el artículo 71 letra r) propuesto originalmente en el proyecto de ley disponía lo siguiente: «Serán admisibles excepciones distintas a las prescritas precedentemente, siempre que se circunscriban a casos especiales, que no atenten contra la explotación normal de la obra, de la interpretación o ejecución y del fonograma, ni causen un perjuicio injustificado a los intereses legítimos del titular de los derechos». Posteriormente, dicho artículo sufrió ciertas modificaciones en orden a limitar los fines bajo los cuáles dichos usos podían ser considerados en la excepción. Finalmente, el artículo 71 letra r) se suprimió por el artículo 71 letra q). 
En primer término, la norma se refiere al uso incidental y excepcional de una obra. Ni la Ley 17.336, ni el reglamento de dicha ley, ni la historia fidedigna de la Ley 20.435 que modifica la anterior definen qué debemos entender por «incidental» $y$ «excepcional».

El sentido natural y obvio de dichas expresiones sugiere, a la luz de la RAE, que incidental se referiría al «dicho o hecho de una cosa: accesoria, de menor importancia»; por su parte, excepción sería aquello que «se aparta de lo ordinario, o que ocurre rara vez». Por ende, para que el uso de una obra protegida por el derecho de autor se encuentre amparado en la presente excepción, debe tratarse de un uso menor o accesorio de la obra original. La norma no entrega un parámetro claro para entender cuándo estamos frente a un uso incidental de una obra, lo que deja abierta la pregunta sobre si el uso autorizado es una porción menor en términos cualitativos o cuantitativos respecto de la obra original. En ambos casos, el uso íntegro de una obra - como en Sony con Universal y Kelly con Arriba Soft Corporation- ${ }^{13}$ no estaría cubierto por la presente excepción. La enunciación de la excepción podría tener un lejano correlato en el tercer factor del fair use, esto es, la cantidad e importancia de la porción utilizada de la obra protegida. Sin embargo, la jurisprudencia norteamericana hoy se encuentra conteste en que la cantidad e importancia debe medirse en términos cuantitativos y cualitativos, siendo, en este último caso, la esencia de la obra el parámetro que los tribunales deben considerar al momento de aplicar la. excepción. La norma chilena pareciera restringirse al aspecto cuantitativo. Así las cosas, en aras de delimitar con mayor claridad el concepto de «incidental», es necesario considerar lo expuesto en el derecho comparado, particularmente en el Reino Unido y en Israel. ${ }^{14} \mathrm{~A}$ la luz de dichos cuerpos normativos, es posible concluir que los usos incidentales son autorizados por la ley cuando: a) la inclusión del fragmento o parte de una obra protegida en otra obra es de poca monta o importancia; b) esta parte es

13. En el segundo caso, la Corte de Apelaciones del Noveno Circuito sostuvo que la copia total de una foto para usarla como thumbnail en los resultados de búsqueda en línea no pesaba contra el fair use. De hecho, la Corte señaló que «si el usuario secundario sólo copia en la medida en que sea necesario para su uso previsto, entonces este factor no pesará en su contra» («if the secondary user only copies as much as is necessary for his or her intended use, then this factor will not weigh against him or her»). Kelly con Arriba Soft Corporation, Corte de Apelaciones del Noveno Circuito, 336 F.3d 811, 2003.

14. En el Reino Unido, la norma para los usos incidentales establece, en lo pertinente: «El copyright en una obra no se infringe por su inclusión incidental en una obra artística, grabación sonora, película o emisión». Por su parte, Israel, en su normativa autoral, establece: «Uso incidental de una obra: un uso incidental de una obra por medio de su inclusión en una obra fotográfica, en una obra cinematográfica o en una grabación de sonido, así como el uso de un tipo de trabajo en el que la obra está incidentalmente contenida, está permitido; en este asunto, la inclusión deliberada de una obra musical, incluyendo sus anexos, letras de canciones o de una grabación de sonido que incorpora tal obra musical en otro trabajo no se considerará como un uso incidental» (Ibáñez, 2013). 
poco significativa en relación con la obra en su conjunto, y c) no existe una intención deliberada de hacer uso del material protegido (Ibáñez, 2013).

En segundo término, el precepto dispone de una serie de propósitos protegidos por la excepción, a saber: la crítica, el comentario, la caricatura, la enseñanza, el interés académico o la investigación. $\mathrm{O}$ sea, tenemos dos filtros que limitan la aplicación práctica de la presente excepción. En primer lugar, debe tratarse de usos incidentales y excepcionales, siendo ambos requisitos copulativos. Y, en segundo lugar, dichos usos incidentales y excepcionales deben efectuarse solamente con miras a los propósitos antedichos, sin que la norma indique con claridad si su enunciación es a título ilustrativo o taxativo. Una interpretación armónica entre los requisitos de usos «incidentales y excepcionales» y los «usos» que la ley establece para la aplicación del precepto hace que en la práctica la norma sea escasamente aplicable. El legislador chileno mezcla en un solo precepto aspectos del fair use con el fair dealing que normativamente resultan inconciliables (Ibáñez, 2013).

Un cuarto aspecto crítico del artículo 71 letra q) de la Ley es que los usos incidentales y excepcionales, efectuados con fines de crítica, comentario, caricatura, enseñanza, interés académico o investigación no deben constituir una explotación encubierta de la obra. El sentido natural y obvio de las expresiones nos indica que una explotación encubierta es aquella no visible, no ostentosa. La exclusión de usos que tengan una connotación económica desconoce la importancia de los mismos en la configuración de una excepción abierta. En efecto, los usos justos reconocen usos no comerciales en su primer factor y en el último, respecto del efecto del mercado de la obra protegida. En ambos casos, se ha concluido que no todo uso comercial infringe los derechos de autor. Sin ir más lejos, la mayoría de las empresas en las que esperamos encontrar casos bien justificados de fair use son comerciales. Así, por ejemplo, el comentario, la crítica, el periodismo, la parodia y la investigación, incluso la publicación de análisis académicos, a menudo son comerciales. Tal como dice Leval: «Si todos esos usos se hallan presuntamente injustos, sólo hallaríamos usos justos en los sermones y en las salas de clases» (Leval, 1997: 1.455). ${ }^{15}$ Por lo demás, admitir que los usos justos no pueden ser comerciales es desconocer el inmenso desarrollo económico que ha tenido Estados Unidos gracias a los usos justos.

Un quinto aspecto crítico de la norma constituye la injustificada exclusión del ámbito de aplicación de la excepción respecto de las obras audiovisuales de carácter documental. Nada consta sobre ello en la historia fidedigna de la ley. ${ }^{16}$ En una co-

15. En nuestra traducción: "Si todos estos usos son presuntamente injustos, entonces el uso justo solo podrá hallarse en sermones y clases magistrales" («If all of these uses are presumptively unfair, then fair use is to be found only in sermons and classroom lectures»).

16. La única referencia al tema es la mención hecha por el senador Letelier de que «en conversaciones con documentalistas tomó conocimiento de que, en ocasiones, terceros hacen uso de una parte de sus 
lumna de opinión, la documentalista Carmen Luz Parot justifica la inserción de la exclusión antes mencionada en base a la inversión detrás de una obra audiovisual de carácter documental y la facilidad con que empresas de comunicación - principalmente canales de televisión - emplean, sin mediar pago ni autorización, imágenes y fragmentos de documentales. ${ }^{17}$ Sin perjuicio de lo anterior, la exclusión pareciera ser injustificada: la excepción exige que se trate de un uso incidental o excepcional (por lo mismo, un canal de televisión no podría exhibir gran parte o una parte importante del documental sin la debida autorización y sin mediar pago), que dicho uso incidental no constituya una explotación encubierta de la obra (por ende, un canal de televisión, en tanto empresa con fines de lucro, no podría valerse de esta excepción para exhibir cualquier fragmento de un documental) y que dicho uso debe enmarcarse dentro de determinados propósitos señalados por la norma.

La exclusión del ámbito de aplicación de la excepción de las obras audiovisuales de carácter documental trae consigo dos consecuencias: i) si bien la excepción se formuló pensando en canales de televisión, igualmente será inaplicable a un colegio o una ONG, es decir, los alumnos y docentes, así como los miembros de una ONG, no podrán valerse de obras audiovisuales para hacer uso de la excepción; y ii) como la excepción excluye obras audiovisuales, surge por ende la pregunta, ¿por qué obras audiovisuales y no otro tipo de obras? ¿Bajo qué mérito se diferencia y/o discrimina un tipo de obras sobre otras?

Cabe hacer presente que la forma en la que se encuentra concebida la actual excepción circunscrita de usos incidentales colisiona con la excepción circunscrita de cita contenida en el artículo 71 letra b) de la Ley. ${ }^{18}$ En efecto, la excepción sobre cita se aplica a aquellos fragmentos que sean utilizados con fines de crítica, ilustración, enseñanza e investigación. Para hacer uso de dicha excepción se exige que la obra haya sido lícitamente divulgada y que se mencione su fuente, título y autor. A su vez, el artículo 71 letra q) permite el uso incidental y excepcional de una obra siempre que se cumpla uno de los cinco propósitos individualizados, destacando para efectos de este análisis los de crítica, enseñanza, interés académico y de investigación. Sobre el particular, la doctrina ha sostenido que el artículo 71 letra q) haría inaplicable la excepción de cita contenida en el artículo 71 letra b), pues permitiría efectuar una cita con los propósitos

obras sin pagar por ello, y que ese uso puede poner término a sus aspiraciones en cuanto al interés de los medios por exhibirla en forma íntegra». Historia de la Ley 20.435 que modifica la Ley 17.336, sobre Propiedad Intelectual, página 608.

17. Véase la columna «El valor de un fragmento» publicada por Ciper Chile el 23 de abril de 2009. Disponible en http://bit.ly/2t7dbFR.

18. Artículo 71 letra b) de la Ley 17.336: «Es lícita la inclusión en una obra, sin remunerar ni obtener autorización del titular, de fragmentos breves de obra protegida, que haya sido lícitamente divulgada, y su inclusión se realice a título de cita o con fines de crítica, ilustración, enseñanza e investigación, siempre que se mencione su fuente, título y autor». 
antedichos sin que la obra sea divulgada previamente y sin necesidad de mencionar su fuente, título y autor (Walker, 2014). Lo mismo ocurriría respecto de la excepción de cita en materia educacional contenida en el artículo 71 letra $\mathrm{m}$ ) de la Ley. ${ }^{19}$

Tal como se encuentra concebida la excepción del artículo 71 letra q), pareciera que la única aplicación práctica de la misma sería en el contexto de la difusión de noticias cuando, en la transmisión de un hecho, se escucha de fondo una canción o se aprecia la transmisión de una película. Bajo ese escenario, se verifica una reproducción y comunicación al público de una obra protegida, de forma incidental, sin autorización del respectivo titular. Pero ¿qué sucede con todos aquellos usos no autorizados que contribuyeron a robustecer los usos justos en Estados Unidos? ¿Podemos esperar que Chile logre el desarrollo económico que Estados Unidos alcanzó gracias al desarrollo del fair use? Con la norma de lege lata, dicho cometido es imposible.

El fair use analizado en este trabajo es inaplicable en Chile como tal. Dicha excepción nace en el derecho anglosajón, en un contexto en que las sentencias judiciales son la principal fuente creadora del derecho. El cometido de la ley (act o statute) en el Common Law es que, en caso de existir ley, los jueces deben fallar conforme a dicha ley (general y abstracta, que usualmente suele ser un tanto vaga, pues se busca que los jueces especifiquen su sentido). Luego, si hay un caso en la jurisprudencia que aplique esa ley particular, el juez debe fallar conforme a dicha ley y a la interpretación jurisprudencial existente para el caso. De no existir ley que resuelva la contienda, se aplican los principios del Common Law (jurisprudencia). Dicha realidad difiere del sistema legalista que nos gobierna, en el que las sentencias emitidas anteriormente por otros jueces no tienen carácter vinculante para el resto de los tribunales, sino una eficacia relativa y no surten efecto excepto en el caso concreto. Por consiguiente, en Chile es muy importante lo que establece la norma legal, porque es lo único vinculante para el juez, quien no crea una excepción basado en una eventual norma de fair use.

Por su parte, la regla de los tres pasos es tan o más ambigua que el fair use. Aún más, no ostenta el poderoso desarrollo económico ni jurisprudencial que ha experimentado su par norteamericano, y su restringida aplicación la ha convertido, en la actualidad, en una excepción sumamente cuestionada.

Siendo inaplicables las excepciones abiertas estudiadas, creemos que es posible que en Chile exista una excepción abierta. Cabe, por ende, delinear los fundamentos

19. Artículo 71 letra m) de la Ley 17.336: «Es lícito, sin remunerar ni obtener autorización del autor, reproducir y traducir para fines educacionales, en el marco de la educación formal o autorizada por el Ministerio de Educación, pequeños fragmentos de obras o de obras aisladas de carácter plástico, fotográfico o figurativo, excluidos los textos escolares y los manuales universitarios, cuando tales actos se hagan únicamente para la ilustración de las actividades educativas, en la medida justificada y sin ánimo de lucro, siempre que se trate de obras ya divulgadas y se incluyan el nombre del autor y la fuente, salvo en los casos en que esto resulte imposible». 
sobre los que se construirá una propuesta de lege ferenda de excepción abierta adaptada a nuestro entorno jurídico social.

\section{Lineamientos para una propuesta normativa de lege ferenda}

\section{Exclusión de obras audiovisuales de carácter documental}

Una adecuada propuesta no puede ni debe excluir ningún tipo de obra. La mera idea de hacer inaplicable la excepción a las obras audiovisuales de carácter documental, so pretexto de un temor infundado, va en detrimento de la sociedad favorecida por las excepciones autorales. No existe un fundamento ni excepción abierta a nivel mundial que contemple la exclusión que contiene la norma chilena.

\section{Explotación comercial}

Las excepciones abiertas reconocidas internacionalmente (fair use y regla de los tres pasos) contienen el componente económico, pues brinda cierta estabilidad en la aplicación de la norma. Sin embargo, como ya hemos expuesto, presumir que todo uso no autorizado con propósitos comerciales es un uso infractor contraviene los principios que han favorecido el desarrollo de la excepción abierta más exitosa a nivel mundial: el fair use. ${ }^{20}$

Al momento de elaborar una obra intelectual, el creador tiene un propósito definido en mente con su creación. Es natural que, bajo dicho propósito, pretenda obtener un provecho económico asociado a la explotación de su obra intelectual. Si una persona hace un uso diferente del originalmente concebido por su creador, y dicho uso no solo se ampara en los propósitos de la excepción abierta, sino que, además, implica una explotación comercial de la obra original, dicho uso debiese estar amparado por la excepción abierta. ${ }^{21}$

20. En tal sentido, el profesor William Patry ha señalado que: "Ese lenguaje, incorporado a última hora a la Sección 107 del título 17 como un regalo para los educadores condujo a años de confusión, en última instancia, a las presunciones de Sony ("todo uso comercial es presuntamente injusto"; "todo uso comercial se traduce en un perjuicio para el mercado"), junto con años de jurisprudencia rígida y desviada, corregida en última instancia en el caso de 2 Live Crew" («that language, added at the 11th hour to Section 107 of title 17 as a sop to educators led to years of confusion in US courts, ultimately to the Sony presumptions ["every commercial use is presumptively unfair"; "every commercial use presumptively results in harm to the market"], and years and years of rigid, mis-directed case law, corrected ultimately in the 2 Live Crew case") (Patry, 2007). Cabe mencionar que, en el caso de 2 Live Crew, el juez Souter de la Corte Suprema señaló que el carácter comercial es otro factor más a considerar por el juez, pero no es un factor determinante. Agregó que mientras más transformador sea un uso, menor importancia tendrá el factor comercial (Patry, 2007).

21. Es el caso de Bill Graham Archives con Dorling Kindersley Ltd., en que la Corte de Apelaciones del Segundo Circuito sostuvo que el uso efectuado — con propósitos históricos- por la editorial Dorling 


\section{Uso justificado para el fin que se persigue}

Las excepciones forman parte del engranaje autoral que propende a un equilibrio de intereses que fomente la actividad creadora. Dicho balance supone un actuar responsable por parte de todos los actores involucrados en la materia. Por lo mismo, el empleo de material protegido por el derecho de autor - susceptible de ser amparado por la excepción abierta- debe efectuarse con cierta racionalidad y discreción, para un fin determinado previsto en la ley, ejecutado en la justa medida para lo que se busca.

\section{Diseño de normativa complementaria}

La formulación de excepciones abiertas supone una redacción abierta, que busca adaptarse a los sucesivos cambios que alteran la forma en que se consumen bienes intelectuales.

En tal sentido, la necesaria vaguedad de su redacción debe subsanarse a través de la dictación de una normativa complementaria - destinada a determinar periódicamente el sentido y alcance de la excepción conforme el devenir de las nuevas tecnologías que modifican la propiedad intelectual- que debiese ser elaborada por una entidad o autoridad no política (o politizada), debiendo, además, tener un carácter prorrogable y con un proceso de creación menos engorroso que la ley. ${ }^{22}$

El riesgo de que dicha normativa complementaria sea elaborada por una autoridad política (o politizada) es que un eventual cambio de gobierno, con distintos lineamientos de política pública en materia autoral, puede conllevar un retroceso o un estancamiento en la dictación de esta normativa complementaria. Circunstancia similar a la que se vivió en Brasil con el proceso de reforma a su normativa autoral (Álvarez Valenzuela, 2011). Ahora bien, es comprensible que la iniciativa antes

\footnotetext{
Kindersley de las siete imágenes de carteles de conciertos de la banda Grateful Dead era fair use, porque el uso efectuado por la editorial fue transformadoramente diferente del propósito original de los carteles, que buscaban concitar la atención y concurrencia respecto de conciertos de la banda. En este caso, además, se reprodujeron las obras en su totalidad. Lo mismo ocurrió en Kelly con Arriba-Soft Corp, en que la Corte de Apelaciones del Noveno Circuito sostuvo que el uso, por parte de Arriba-Soft, de las fotografías tomadas por Kelly para indexarlas como thumbnails en su motor de búsqueda eran fair use, enfatizando a dichos efectos que el uso de las imágenes servía a un propósito diferente de las que tuvo Kelly al tomarlas, mejorando precisamente el acceso a información en internet (Samuelson, 2015).

22. En Chile, la modificación sustantiva de la Ley de Propiedad Intelectual tomó cuarenta años. Es evidente que dichos cambios suponen una voluntad política. «La estructura de la Ley sobre Derecho de Autor, y particularmente,su historia legislativa, indican que la verdadera función del uso justo es permitir que la Ley sobre Derecho de Autor, evolucione en respuesta a nuevos desafíos sin necesidad de intervención legislativa» («The structure of the Copyright Act and the history of copyright law indicate that the true function of fair use is to enable copyright law to evolve in response to new challenges without necessitating legislative intervention») (Sag, 2005: 19).
} 
mencionada merezca reparos por su aparente inconstitucionalidad. De acuerdo a lo dispuesto en el inciso final del artículo 19 número 25 de nuestra Carta Fundamental, se hacen aplicables a la propiedad intelectual e industrial los incisos segundo, tercero, cuarto y quinto del precedente articulo 19 número 24 de la CPR - que regula el derecho de propiedad-, en cuyo inciso segundo se señala que «sólo la ley puede establecer el modo de adquirir la propiedad, de usar, gozar y disponer de ella y las limitaciones y obligaciones que deriven de su función social». Por lo mismo, si por mandato constitucional existe un principio de reserva legal que atribuye a la ley la facultad exclusiva de establecer excepciones a la propiedad, que un reglamento u otra clase de normativa especifique el sentido y alcance de una excepción a la propiedad puede ser problemático en términos constitucionales. ${ }^{23}$ Sin perjuicio de lo anterior, cabe tener presente dos aspectos del todo relevantes.

En primer término, el Tratado de Libre Comercio con Estados Unidos faculta a los Estados partes para que mediante un procedimiento legislativo, o inclusive administrativo, se puedan establecer excepciones distintas de las previstas en la Ley (artículo 17.7.5 letra d) numeral 1). ${ }^{24}$ De esa forma, la Oficina de Copyright de la Biblioteca del Congreso de Estados Unidos puede establecer excepciones distintas a las previstas en la misma ley con una vigencia temporal y prorrogable de tres años, a fin de permitir la actualización de la ley sin necesidad de requerir un continuo procedimiento legislativo que suele ser complejo. ${ }^{25}$ Sobre el particular, durante la deliberación legislativa

23. Así se sostuvo por varias autoridades que participaron en el debate de la nueva Ley de Propiedad Intelectual. Historia de la Ley 20.435, páginas 111 y 122.

24. Artículo 17.7 numeral 5): «Con el fin de otorgar protección jurídica adecuada y recursos jurídicos efectivos contra la acción de eludir las medidas tecnológicas efectivas que sean utilizadas por los autores, artistas intérpretes o ejecutantes y productores de fonogramas en relación con el ejercicio de sus derechos y que respecto de sus obras, interpretaciones o ejecuciones y fonogramas protegidos por los derechos de autor y derechos conexos, restrinjan actos no autorizados [...] d) cada Parte deberá limitar las restricciones y excepciones a las medidas que implementen los subpárrafos a) y b) a ciertos casos especiales que no menoscaben la adecuada protección legal ni la eficacia de los recursos legales destinados a impedir la elusión de medidas tecnológicas efectivas. En particular, cada Parte podrá establecer excepciones o limitaciones para abordar las siguientes situaciones y actividades de acuerdo con el subpárrafo e): i) cuando se demuestre o reconozca en un procedimiento legislativo o administrativo establecido por ley, que se produce un impacto adverso, real o probable, sobre usos no infractores de una determinada clase de obras o sobre excepciones o limitaciones al derecho de autor o derechos conexos respecto de una clase de usuarios, a condición de que cualquier limitación o excepción adoptada en virtud de este subpárrafo d) i) tenga efecto durante un período no superior a tres años contados a partir de la fecha de la conclusión de tal procedimiento».

25. Así, sin ir más lejos, durante el 2006, la Oficina de Copyright de la Biblioteca del Congreso de Estados Unidos autorizó la supresión de medidas tecnológicas de protección sobre las obras tratándose de los siguientes casos: 1) obras audiovisuales incluidas en bibliotecas de centros educativos, universidades o centros de estudios audiovisuales, cuando se utilicen fragmentos de esas obras en el aula y con propósito educativo; 2) programas informáticos y videojuegos distribuidos en formatos que hayan quedado 
que dio a luz a la Ley 20.435, el profesor Alberto Cerda sostuvo: «Sobre la base de lo precedente, cabe considerar todavía al Legislativo la posibilidad de conceder facultades análogas a las de la Oficina de Copyright de Estados Unidos para que alguna(s) repartición(es) pública(s) autorizara(n) temporalmente determinados usos de las obras ante circunstancias calificadas». ${ }^{26}$ La posibilidad de revisar periódicamente el sentido y alcance de las excepciones, junto con la posible creación de nuevas, permite la rauda adaptación de la propiedad intelectual a los cambios tecnológicos, que modifican no sólo el entorno autoral, sino también el entorno social.

Un segundo punto a tratar, en el evento que no sea jurídicamente deseable que una repartición pública establezca una normativa complementaria que determine el alcance de excepciones abiertas, se refiere a la potestad reglamentaria y a la reserva legal. La potestad reglamentaria del presidente de la República tiene rango constitucional, es una potestad normativa secundaria, su titularidad corresponde al presidente de la República, es discrecional y se expresa en decretos y reglamentos (Carmona, 2001). Sin perjuicio de lo anterior, se ha observado en el último tiempo una paulatina relativización del concepto de reserva legal por parte de la jurisprudencia constitucional. Lo anterior se traduce en la noción del reglamento como una técnica de colaboración en la ejecución de la ley, atendida la existencia de materias que por su complejidad, mutabilidad o tecnicismo no pueden ser abordadas de forma efectiva por el legislador (Carmona, 2001: 225). En virtud de dicha reserva legal relativa, es posible que el Ejecutivo dicte una norma reglamentaria destinada a establecer pautas o criterios para implementar de mejor forma una norma legal que tenga una configuración abierta o que sea intransitiva, esto es, que la norma se limite a instruirle al implementador que desarrolle las reglas (Guiloff, 2012: 127-147). El carácter no transitivo de la excepción de usos justos es necesario en procura del propósito de la norma legal autoral, esto es, servir de contrapeso en la estructura de intereses que concurren en materia de derechos de autor, lo que permite que la sociedad en su conjunto (función social de la propiedad) acceda a obras protegidas por la ley sin mediar autorización ni pago alguno del titular, bajo ciertos supuestos definidos previamente en la ley, con la flexibilidad necesaria para que la norma logre adaptarse a los cambios tecnológicos que alteran cotidianamente la configuración del derecho de autor.

Así las cosas, compartimos la redefinición del rol de la reserva de ley que apunta Guiloff, en aras de los objetivos que persiga una norma legal dada. ${ }^{27}$

obsoletos y que requieran los medios originales o hardware para ser accedidos, cuando se trate de preservar o archivar las obras digitales para una biblioteca o archivo;3) programas informáticos protegidos por dispositivos hardware cuando éstos ya no se fabriquen o no puedan repararse.

26. Ver Historia de la Ley 20.435, página 137.

27. Un ejemplo de norma no transitiva que toca derechos fundamentales es el artículo 32 de la Ley 19.300 sobre Bases Generales del Medio Ambiente, pues se trata de una norma legal que establece las 
Con todo, en el evento de que se efectúen reparos de constitucionalidad sobre la materia en comento, cabe destacar que la normativa reglamentaria dictada por el Ejecutivo no entraría a crear una nueva excepción de usos justos, sino a establecer pautas o criterios para la mejor implementación de una excepción o limitación al derecho de propiedad intelectual ya contenida en una ley.

En definitiva, no es sostenible ni operativo en nuestro ordenamiento constitucional plantear una tesis basada en una idea rígida de la reserva legal, ya que no siempre la pérdida de intensidad o flexibilización de las leyes puede verse como un fenómeno contrario a las exigencias y al rol de la reserva legal. Por el contrario, flexibilizar no necesariamente significa relativizar o debilitar la reserva, ya que en la relación leyreglamento, este último debe regular todo lo indispensable para garantizar la aplicación de la ley. Debe propenderse a una visión de colaboración entre el reglamento y una ley (Cazor y Guiloff, 2010).

\section{Confección de código de buenas prácticas}

El desarrollo del proceso creativo se da al interior de contextos sociales. La participación de la sociedad como consumidora y posterior creadora de bienes intelectuales es indesmentible. Es por ese estrecho vínculo con la sociedad en su conjunto, que ésta debe ejercer un rol activo en la elaboración de códigos de buenas prácticas que sirvan como guías - no vinculantes para la judicatura- para educar a los ciudadanos en el adecuado uso de materiales protegidos por el derecho de autor. Todo ello, en el marco de iniciativas que tiendan a robustecer la excepción genérica y su consabida ambigüedad. Iniciativas similares se llevaron exitosamente a cabo en Estados Unidos respecto de los documentalistas, mediante la confección de una guía de buenas prácticas que permitió la realización de documentales que de otro modo - quizás por temor- no se hubieran jamás realizado. Dichas guías bien podrían ser elaboradas por ONG vinculadas a la materia, o por la Dirección de Bibliotecas, Archivos y Museos.

\section{Usos que agreguen valor a la obra y que no la sustituyan}

El profesor Tim Wu introduce un novedoso criterio para determinar la procedencia o no del fair use: «Si el uso agrega un nuevo valor a la obra, es un uso justo, pero si

\footnotetext{
formalidades para promulgar «normas de calidad», su ámbito de aplicación y la indicación que deberán establecer niveles que originan situaciones de emergencia ambiental. Acto seguido, la norma efectúa una remisión al reglamento para que éste establezca el procedimiento de dictación de normas de calidad ambiental, señalando que este último deberá considerar al menos las etapas de análisis técnico y económico, de desarrollo de estudios científicos de consultas a organismos competentes -ya sea públicos o privados- y de análisis de las observaciones formuladas, todo ello bajo una adecuada publicidad.
} 
sustituye a la obra original, ya no es un uso justo». ${ }^{28} \mathrm{Al}$ «agregarle un nuevo valor a la obra» se implicita el carácter transformador del uso, imprimiéndole a la obra un nuevo contenido, una nueva utilidad. La propuesta normativa del profesor Wu sintetiza el camino que ha seguido la jurisprudencia norteamericana en el último tiempo, asignándole mayor peso a aquellos usos que transforman o imprimen una nueva utilidad a la obra original. Desde luego, la propuesta topa con un gran obstáculo, cual es la situación de usos que no agregan un nuevo valor a la obra, como, por ejemplo, las reproducciones de materiales hechas para fines educacionales. A nuestro juicio, en dichas circunstancias debiesen primar otros factores que inclinen la balanza hacia un uso justo, si las circunstancias del caso así lo ameritan. La propuesta del profesor Wu excluye aquellos usos de obras ajenas que operan como bienes sustitutivos respecto de la obra original.

\section{Libertad de expresión como fundamento}

El sustento último de la excepción abierta es la protección constitucional de la libertad de expresión, porque en ocasiones, para expresar una opinión legítimamente puede que sea necesario utilizar obras ajenas, como, por ejemplo, al efectuar una crítica de una película o de un libro. Si para efectuar una crítica o comentario en los términos antes mencionados, fuese necesario previamente pedir autorización y pagar el costo que fijen los titulares de la obra criticada, se estaría afectando seriamente la libertad de expresión resguardada constitucionalmente.

\section{Una propuesta de lege ferenda}

Al tenor de los lineamientos ya mencionados, nuestra propuesta normativa de lege ferenda que venga a superar las deficiencias que presenta la actual redacción de la norma del artículo 71 letra q) sería en los siguientes términos:

Fuera de las excepciones previstas en el presente título, será lícito el uso de una obra protegida, con el propósito de crítica, comentario, caricatura, enseñanza, interés académico o de investigación, siempre que dicho uso sea realizado, en la medida justificada, para el fin que se persigue y que no constituya un sustituto que afecte la explotación comercial de la obra.

En primer término, se busca que la norma tenga una aplicación residual, es decir, se aplique en los casos no cubiertos por las excepciones precedentes. De esa forma, se evita un conflicto normativo con otras excepciones, como es el caso del derecho de cita, ya estudiado.

28. Véase el artículo «Bits debate: mixing it up over remixes and fair use» de Saul Hansell, publicado en The New York Times el 16 de enero de 2008. Disponible en http://nyti.ms/2rNZCHz. 
Por otro lado, se conserva la enunciación de los propósitos, lo que de esa forma otorga un marco estable a una excepción tan flexible como la de marras.

El uso debe ser efectuado «en la medida justificada para el fin que se persigue». Este criterio busca otorgar cierta proporcionalidad al uso de una obra ajena. En ese sentido, se asemeja al tercer factor de la sección 107 de la Copyright Act de Estados Unidos, esto es, la cantidad e importancia de la porción utilizada de la obra protegida. La ventaja, en comparación con la norma actual, es que la proporcionalidad se entrega en base a un parámetro claro: la finalidad que persigue el uso de la obra ajena.

Se incorpora el factor comercial, pero de una forma acotada, esto es, limitado a que el uso de la obra no constituya un sustituto y que no afecte la explotación comercial de la obra. Los bienes sustitutivos, por lo general, tenderán a ser copias del original y, por lo mismo, afectarán la explotación comercial de la obra original. La exclusión de bienes sustitutivos de la presente excepción previene que una mera copia pueda ampararse dentro de la excepción genérica. Dicho estándar entrega una mayor certeza en su aplicación, en relación con la explotación encubierta de una obra, que contiene la norma actual.

Cabe añadir que una óptima excepción genérica debe contar — necesariamentecon una robustecida normativa complementaria que le brinde a un ente público la facultad de autorizar - temporalmente-ciertos usos de obras protegidas o, al menos, que permita la dictación de normas que otorguen pautas claras para la implementación efectiva de la excepción genérica, bajo supuestos sumamente calificados. Junto con ello, es clave el rol de agrupaciones cívicas que confeccionen «códigos de buenas prácticas» que ilustren de mejor manera sobre el uso de obras ajenas en el contexto de la excepción genérica en estudio.

Para graficar con claridad la diferencia entre nuestra propuesta normativa y la norma actualmente contenida en la ley, cabe tener presente los ejemplos que muestra el cuadro 1, no subsumibles en las excepciones circunscritas señaladas en la ley.

\section{Conclusión}

Todo el estudio que hemos realizado se basa en el supuesto de que una ley autoral supone un balance de intereses, expresado - entre otros medios- en un sistema de limitaciones y excepciones al derecho de autor.

Sin embargo, quisiéramos proponer el siguiente ejercicio: ¿qué sucedería si no hubiese excepciones al derecho de autor? En un mundo sin excepciones al derecho de autor, las siguientes conductas serían ilícitas: todas las citas efectuadas en este trabajo; una biblioteca para no videntes que reproduzca y adapte a sistema braille obras no disponibles en dicho formato; un profesor que reproduzca y distribuya a sus alumnos fragmentos de Sandokán como material de lectura; una madre que grabe a su hija bailando una canción de Prince y después suba dicho material a Youtube; 


\section{Cuadro 1.}

\begin{tabular}{|c|c|c|}
\hline Caso & Excepción actual & Propuesta normativa \\
\hline $\begin{array}{l}\text { La demanda intentada por los titulares } \\
\text { de los derechos de una canción contra } \\
\text { un joven que sube un video en Youtube } \\
\text { tocando dicha canción en guitarra. }\end{array}$ & $\begin{array}{l}\text { El derecho de cita cubre fragmentos } \\
\text { breves, acá se reproduce la obra íntegra- } \\
\text { mente. La excepción de usos incidentales } \\
\text { no permite que se utilice una obra en su } \\
\text { totalidad. Por lo mismo, dicho uso sería } \\
\text { ilícito actualmente. }\end{array}$ & $\begin{array}{l}\text { Al ponderar los elementos de la propuesta } \\
\text { normativa, cabe advertir que el uso efec- } \\
\text { tuado por el joven no constituye un susti- } \\
\text { tuto de la obra original (nadie escuchará el } \\
\text { cover pensando que es el tema original). } \\
\text { Luego, no existe en nuestro ejemplo una } \\
\text { explotación comercial de la obra (en } \\
\text { nuestro ejemplo, el joven no obtiene una } \\
\text { ganancia asociada a la reproducción y } \\
\text { comunicación al público de su versión). }\end{array}$ \\
\hline $\begin{array}{l}\text { La demanda intentada por los titulares } \\
\text { de los derechos de autor del afiche de la } \\
\text { película The three little pigs (Disney, 1933) } \\
\text { contra el autor de un libro sobre política } \\
\text { que utiliza el afiche de la película de } \\
\text { Disney como portada del mismo. }\end{array}$ & $\begin{array}{l}\text { El derecho de cita cubre fragmentos } \\
\text { breves, acá se reproduce íntegramente el } \\
\text { afiche de la película, por ende, tampoco } \\
\text { es un uso incidental. Del mismo modo, } \\
\text { el autor pretenderá obtener un beneficio } \\
\text { económico con la venta del libro, por lo } \\
\text { que se configura una explotación comer- } \\
\text { cial del mismo. }\end{array}$ & $\begin{array}{l}\text { Al ponderar los elementos de la propuesta } \\
\text { normativa, cabe advertir que el uso se } \\
\text { hace con un propósito de crítica; en la } \\
\text { medida justa para transmitir dicha crítica; } \\
\text { no siendo un sustituto de la obra original } \\
\text { (nadie pensará que un libro de política } \\
\text { sustituye un cuento infantil) que afecte } \\
\text { la explotación comercial de la película de } \\
\text { Disney. }\end{array}$ \\
\hline $\begin{array}{l}\text { La demanda intentada por los titulares } \\
\text { de los derechos de autor de varios books } \\
\text { fotográficos sobre modelos de pasarela } \\
\text { contra el artista que utiliza esas fotogra- } \\
\text { fías o parte de ellas - junto con otras } \\
\text { fotografías - para hacer un montaje } 0 \\
\text { collage que denuncie la anorexia impuesta } \\
\text { como estándar en la moda. }\end{array}$ & $\begin{array}{l}\text { El derecho de cita cubre fragmentos } \\
\text { breves, acá se reproducen íntegramente } \\
\text { las fotos. Del mismo modo, dicho uso no } \\
\text { se subsume en fragmentos breves. Por } \\
\text { último, si el artista que monta el collage } \\
\text { quisiera explotar comercialmente su } \\
\text { obra, dicho uso excede la excepción antes } \\
\text { mencionada. }\end{array}$ & $\begin{array}{l}\text { Al ponderar los elementos de la propuesta } \\
\text { normativa, cabe advertir que el uso se } \\
\text { hace con un propósito de crítica; en la } \\
\text { medida justa para transmitir dicha crítica; } \\
\text { no siendo un sustituto de la obra original } \\
\text { (nadie pensará que un collage de crítica } \\
\text { reemplazará un book fotográfico dirigido a } \\
\text { agencias de modelos) que afecte a explo- } \\
\text { tación comercial de los books fotográficos } \\
\text { (no se afecta el mercado de los fotógrafos } \\
\text { de modelos, pues la calidad de las fotos } \\
\text { no se deteriorará por su aparición en un } \\
\text { collage de crítica). }\end{array}$ \\
\hline $\begin{array}{l}\text { La demanda intentada por los titulares } \\
\text { de los derechos de autor de un artículo } \\
\text { científico norteamericano, recientemente } \\
\text { publicado, contra el profesor chileno que } \\
\text { los traduce para los alumnos de su clase. }\end{array}$ & $\begin{array}{l}\text { La excepción circunscrita de traducción se } \\
\text { sitúa en supuestos limitados (la traducción } \\
\text { debe ser hecha por bibliotecas o archivos, } \\
\text { sin fines lucrativos y transcurridos tres } \\
\text { años desde la primera publicación; o debe } \\
\text { tratarse de traducciones hechas para uso } \\
\text { personal). Suponiendo que el profesor no } \\
\text { se encuentra en ninguna de las circuns- } \\
\text { tancias anteriormente mencionadas, su } \\
\text { proceder sería ilícito. Bajo la excepción } \\
\text { de usos incidentales, pese a que exista } \\
\text { un propósito educacional y que no exista } \\
\text { explotación comercial de la obra, se usa la } \\
\text { obra en su totalidad, por lo que el uso deja } \\
\text { de ser excepcional. }\end{array}$ & $\begin{array}{l}\text { Según nuestra propuesta normativa, } \\
\text { la acción del docente sería lícita, pues } \\
\text { dicho uso se efectúa en la medida } \\
\text { justificada para el fin que se persigue } \\
\text { (docencia), sin constituir un sustituto que } \\
\text { afecte la explotación comercial de la obra } \\
\text { (difícilmente el texto empleado en una } \\
\text { clase en particular podrá reemplazar, por } \\
\text { ejemplo, un compendio de textos sobre } \\
\text { la materia publicado posteriormente por } \\
\text { una editorial). }\end{array}$ \\
\hline
\end{tabular}




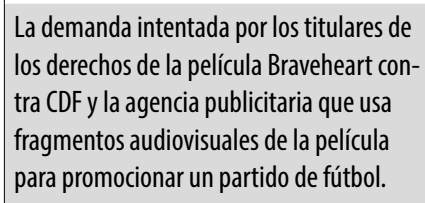

Dado el formato de la publicidad televisiva, resulta complejo mencionar la fuente, el título de la obra y el autor de la misma, por lo que el uso no estaría cubierto por la excepción de cita. Bajo la excepción de usos incidentales, pese a ser un uso incidental, no hay un propósito que no se enmarque claramente en los supuestos de la norma (podría ser caricatura) y existe una explotación comercial asociada a la reproducción de la obra original.
Aplicando nuestra propuesta normativa, si bien no existe claridad respecto de si el uso se subsume en los propósitos contenidos en la norma (podría ser caricatura), sí se usa una porción adecuada para el fin perseguido (caricaturizar la batalla deportiva como un evento bélico), y no constituye un bien sustitutivo respecto de la obra original que afecte la explotación comercial del film.

un alumno que reproduzca y comunique públicamente a su clase una imagen de un cuadro de Dalí para disertar sobre el surrealismo; la fotocopia de los apuntes de clase de un compañero; el respaldo que hago en el disco duro de mi computador respecto de algún material; la crítica de un libro reproduciendo fragmentos o parte de la trama del mismo, etcétera.

En un mundo sin excepciones al derecho de autor, se vulneraría la libertad de expresión, pues el titular de una obra podría censurar - a través de acciones judiciales- aquel uso de su obra para fines de crítica o parodia, por estimar que dichos usos dañan su reputación.

El derecho de autor no es un arma a disposición del titular que le permita tener un control total sobre el uso que se haga de su obra por terceros, llegando incluso a censurar el libre discurso. Por el contrario, el derecho de autor constituye un conjunto de normas establecidas sobre la base de diversos intereses. Es precisamente esa última premisa (la convergencia de intereses), la que no ha tenido una recepción muy clara durante el último tiempo en nuestra legislación, pues ha favorecido a los titulares en desmedro de la sociedad que accede y consume las obras creativas.

Ese desequilibrio proviene de una tradición francesa que hoy resulta cuestionable. Bajo el pretexto de respetar dicha tradición, el constituyente chileno omitió una pregunta esencial: ¿por qué existe el derecho de autor? El vínculo entre creador y creación que propugna la tradición francesa (teoría de la personalidad) es la razón de por qué nuestro constituyente nunca se formuló la pregunta esencial antes mencionada. Tradición francesa que nace hace más de dos siglos ${ }^{29} \mathrm{y}$ que nos sigue gobernando hasta el día de hoy. Tradición que hoy día tiene a Francia como uno de los países más conservadores en temas de propiedad intelectual. No por nada, la industria del software en Francia es nula en comparación con el robusto desarrollo que ha tenido en Estados Unidos, gracias precisamente a la inclusión de excepciones como los usos

29. Hace dos siglos, la tecnología que ha modificado el derecho de autor sucesivamente no existía. 
justos. Sin ir más lejos, es posible apreciar que quienes cuentan con sistemas de excepciones más robustos, incluyendo normas de usos justos, son precisamente los países más desarrollados, situación que no se condice con las necesarias flexibilidades que los países menos aventajados requieren para lograr un desarrollo mínimamente equitativo (Álvarez Valenzuela, 2011).

Una normativa equilibrada se elabora partiendo por la razón misma que impulsa al derecho de autor, se protege al autor: porque como sociedad queremos fomentar la creación de obras, y porque queremos que la sociedad pueda acceder a dichas obras. Sobre este punto, cabe destacar lo señalado recientemente por la Corte Suprema de Delhi en India ${ }^{30}$ respecto de la demanda presentada por un grupo de editores de artículos académicos por la reproducción no autorizada de extractos de textos académicos por parte de un centro de fotocopia. La Corte, en su considerando 8o, señaló:

Copyright, especially in literary works, is thus not an inevitable, divine, or natural right that confers on authors the absolute ownership of their creations. It is designed rather to stimulate activity and progress in the arts for the intellectual enrichment of the public. Copyright is intended to increase and not to impede the harvest of knowledge. It is intended to motivate the creative activity of authors and inventors in order to benefit the public.

Para subsanar dicho desequilibrio, se llevó a cabo la enmienda legal a la actual normativa autoral, a través de la Ley 20.435 que incorporó un robusto catálogo de excepciones al derecho de autor. Dentro de dichas excepciones se adoptó - por primera vez - una excepción circunscrita de usos incidentales, que tuvo un germen de usos justos.

La excepción abierta incorporada en la legislación chilena tiene una redacción confusa y difícilmente aplicable en la práctica. No se siguió el camino de los usos justos norteamericanos, ni de la regla de los tres pasos del Convenio de Berna, sino que se creó una norma nueva. Se siguió una tercera ruta: crear algo nuevo. Esa apuesta demostró una peculiaridad del legislador chileno: durante cuarenta años intervino lo mínimo en la propiedad intelectual (limitándose sólo a aumentar las sanciones), no obstante, súbitamente, legisló sobre el tema, y creó una norma nueva (no acudiendo a normas de probada experiencia, con el objeto de adaptarla conforme nuestra realidad). Lo anterior ha motivado las críticas que hemos formulado en este trabajo. Cabe reconocer que existe un progreso, pero dicho progreso es insuficiente.

El legislador desconoció que la incerteza intrínseca de la norma es necesaria, en aras de que la norma cumpla el cometido de adaptar la legislación autoral a las suce-

30. The Chancellor, Masters and Scholars of the University of Oxford and ORS con Rameshwari Photocopy Services, Corte Suprema de Delhi en Nueva Delhi, CS(OS) 2439/2012, 16 de septiembre de 2016. Disponible en http://bit.ly/2dIqBCg. 
sivas innovaciones tecnológicas, que alteran constantemente la configuración interna del derecho de autor.

En tal sentido, creemos que es posible la existencia de una excepción abierta en Chile. Creemos que existe un temor - quizás algo fundado- sobre la aplicación práctica que hagan los tribunales cuando se vean enfrentados a esta norma. Pero no por un temor a la judicatura se puede cerrar la puerta a una excepción abierta a la luz de los usos justos y sus consabidos beneficios. Es un trabajo que involucra no solo educar a los jueces, sino a la sociedad en general, respecto del derecho de autor y cómo la tecnología paulatinamente se inmiscuye en todas las áreas del derecho.

Nuestra propuesta de lege ferenda contribuye a enriquecer la normativa de excepciones autorales dotándola de un verdadero significado, al recoger las indicaciones que hemos formulado, las que tienen por objeto enmendar el curso de la excepción circunscrita de usos incidentales actual. Su importancia, no sólo en el esquema legal sino económico, es de suma trascendencia y contribuiría a una sociedad más enriquecida culturalmente, con valores democráticos sólidos, porque una sociedad que consume obras intelectuales con más facilidad es una sociedad que cuenta con más herramientas para volver a crear, pues tal como dijo Yolanda Reyes, en Los oficios de la imaginación:

Cuando llegó la gente al mundo, llegó también el asombro. Y la curiosidad humana, casi tan vieja como el mar, empezó a crear relatos para contestar sus preguntas. Pero la cadena ha resultado infinita: de cada nueva pregunta surgen nuevas creaciones y las nuevas creaciones nos generan más preguntas (Reyes y Da Coll, 2005).

\section{Referencias}

Álvarez Valenzuela, Daniel (2011). «En busca de equilibrios regulatorios: Chile y las recientes reformar al derecho de autor». Programa de Innovación, Tecnología y Propiedad Intelectual; International Centre for Trade and Sustainable Development. Disponible en http://bit.ly/2tGR6vf.

Álvarez Valenzuela, Daniel y Marco Correa Pérez (2017). «La doble dimensión del derecho de autor: el acceso a la cultura y los derechos de autor». Revista de Derecho Público, 85 (2): 11-32. DOI: 10.5354/0719-5249.2016.44958.

Carmona, Carlos (2001). «Tres problemas de la potestad reglamentaria: legitimidad, intensidad y control». Revista de Derecho del Consejo de Defensa del Estado, 3. Disponible en http://bit.ly/2trBnnd.

Cazor, Kamel y Matías Guiloff (2010). «La reserva de la ley y la necesidad de redifinir su función en el estado constitucional chileno». Coloquio de Justicia de la Facultad de Derecho de la Universidad Diego Portales. Disponible en http://bit. ly/2t2MnUV. 
Crews, Kenneth (2017). «Fair use». Copyright Advisory Office de Universidad de Columbia. Disponible en http://bit.ly/2qc4454.

Guiloff, Matías (2012). «Operativizando la relación ley-reglamento: una propuesta de redefinición del rol de la reserva legal». Revista de Derecho (Valdivia), 25 (1): 127-147. DOI: 10.4067/So718-09502012000100006.

HeIns, Marjorie y Tricia BeckLes (2005). Will fair use survive? Free expression in the age of copyright control. Nueva York: Brennan Center for Justice NYU School of Law, Democracy Program.

IвÁÑEZ, Carolina (2013). «Fair use como modelo de flexibilización del derecho de autor». Memoria para optar al grado de Licenciado en Ciencias Jurídicas y Sociales, Facultad de Derecho, Universidad de Chile.

MAdison, Michael (2004). «A pattern-oriented approach to fair use». William and Mary Law Review, 45 (4): 1525-169o. Disponible en http://bit.ly/2sDtUQ5.

Magliona, Claudio y Macarena LóPEZ (2010). «Derecho de autor y nuevas tecnologías». Documentos de clase.

Patry, William (2007). «Fair use, Israel and the IIPA». The Patry Copyright Blog. 26 de febrero. Disponible en http://bit.ly/2sNQ4Ob.

ReYes, Yolanda e Ivar DA Coll (2005). Los oficios de la imaginación. Bogotá: Dirección Nacional de Derecho de Autor de Colombia.

Rogers, Thomas y Andrew Szamosszegi (2007). Economic contribution of industries relying on fair use. Washington DC: Computer \& Communication Industry Association.

SAG, Matthew (2005). «God in the machine: a new structural analysis of copyright's fair use doctrine». Michigan Telecommunication and Technology Law Review, 11 (2): 382-435. Disponible en http://bit.ly/2sDHzqE.

Samuelson, Pamela (2009). «Unbundling fair uses». Fordham Law Review, 77 (5): 2537-2621. Disponible en http://bit.ly/2s8MpIJ.

-. (2015). «Possible Futures of Fair Use». Washington Law Review, 90 (2): 815-868. Disponible en http://hdl.handle.net/1773.1/1464.

Schmitz, Christian (2009). «Propiedad intelectual, dominio público y equilibrio de intereses». Revista Chilena de Derecho, 36 (2): 343-367. DOI: 10.4067/ So718-34372009000200006.

Senftleben, Martin (2010). "The international three-step test: a model provision for EC fair use legislation». Journal of Intellectual Property, Information Technology and E-Commerce Law, 1 (2): 67-82. Disponible en http://bit.ly/2s3QbIi.

STIM, Rich (2010). «Measuring fair use: the four factors». Copyright \& Fair Use Stanford University Libraries. Disponible en http://stanford.io/2t8bfxB.

Oficina de Copyright DE Estados Unidos (1983). «Reproduction of copyrighted works by educators and librarias». Washington DC: Autor. Disponible en http:// bit.ly/2sOulpd. 
WALKer, Elisa (2014). Manual de propiedad intelectual. Santiago: Thomson Reuters.

\section{Sobre el autor}

Carlos Araya Paz es abogado. Licenciado en Ciencias Jurídicas y Sociales de la Facultad de Derecho de la Universidad Adolfo Ibáñez. Diplomado en Propiedad Intelectual de la Pontificia Universidad Católica de Chile. Abogado del estudio jurídico García \& Magliona Abogados. Su correo electrónico carlosarayapaz@gmail.com. 